\title{
Delayed developmental changes in neonatal vocalizations correlates with variations in ventral medial hypothalamus and central amygdala development in the rodent infant: effects of prenatal cocaine
}

\author{
E.T. Cox ${ }^{1,3,5,{ }^{*}, \text { C.W. Hodge }}{ }^{1,2,3}$, M.J. Sheikh ${ }^{2}$, A.C. Abramowitz ${ }^{2}$, G.F. Jones ${ }^{2}$, A.W. \\ Jamieson-Drake $^{3}$, P.R. Makam ${ }^{2}$, P.S. Zeskind ${ }^{4}$, and J.M. Johns ${ }^{1,2,3}$ \\ ${ }^{1}$ University of North Carolina, Curriculum in Neurobiology, Charlotte, NC \\ ${ }^{2}$ University of North Carolina, Department of Psychology, Charlotte, NC \\ ${ }^{3}$ University of North Carolina, Department of Psychiatry, Charlotte, NC \\ ${ }^{4}$ Levine Children's Hospital at Carolinas Medical Center, Charlotte, NC \\ ${ }^{5}$ University of Utah, Center for Integrated Neuroscience and Human Behavior, The Brain Institute
}

\section{Abstract}

\begin{abstract}
While variations in neonatal distress vocalizations have long been shown to reflect the integrity of nervous system development following a wide range of prenatal and perinatal insults, a paucity of research has explored the neurobiological basis of these variations. To address this, virgin Sprague-Dawley rats were bred and divided into three groups: (1) untreated, (2) chronic-cocaine treated $(30 \mathrm{mg} / \mathrm{kg} / \mathrm{day}$, gestation days (GDs) $1-20)$; or (3) chronic-saline treated (2mg/kg/day, GDs 1-20). Pregnant dams were injected with Bromodeoxyuridine (10mg/kg) on GDs $13-15$ to label proliferating cells in limbic regions of interest. Ultrasonic vocalizations (USVs) were recorded on PNDs 1, 14, and 21, from one male and female pup per litter. Variations in acoustic properties of USVs following cocaine-exposure were age and sex-dependent including measures of total number, total duration and amplitude of USVs, and percent of USVs with at least one harmonic. Following USV testing brains were stained with standard fluorescent immunohistochemistry protocols and examined for variations in neuronal development and if variations were associated with acoustic characteristics. Limbic region developmental differences following cocaineexposure were sex- and age-dependent with variations in the ventral medial hypothalamus and central amygdala correlating with variations in vocalizations on PND 14 and 21. Results suggest maturation of the ventral medial hypothalamus and central amygdala may provide the basis for variations in the sound and production of USVs. As vocalizations may serve as a neurobehavioral marker for nervous system integrity, understanding the neurobiological basis of neonatal vocalizations may provide the basis for early intervention strategies in high-risk infant populations.
\end{abstract}

(C) 2012 Elsevier B.V. All rights reserved.

"Correspondence to: Elizabeth T. Cox, The University of North Utah, Center for Integrated Neuroscience and Human Behavior, The Brain Institute, Department of Pediatrics, Sorenson Molecular Biotechnology Building, SMBB, 36 South Wasatch, Salt Lake City, UT 84112-5001, USA, elizabeth.cox@utah.edu, (p) (801)587-1423; (f) (801)587-8285.

Publisher's Disclaimer: This is a PDF file of an unedited manuscript that has been accepted for publication. As a service to our customers we are providing this early version of the manuscript. The manuscript will undergo copyediting, typesetting, and review of the resulting proof before it is published in its final citable form. Please note that during the production process errors may be discovered which could affect the content, and all legal disclaimers that apply to the journal pertain. 


\section{Keywords}

neonate; vocalization; development; limbic; prenatal; cocaine

\section{Introduction}

Variations in the acoustic parameters of neonatal crying have been consistently shown to reflect the integrity of central nervous system development in the human infant. Infants with such prenatal and perinatal insults as brain damage, prenatal malnutrition, and prenatal drug exposure, have been differentiated by a wide range of measures of infant crying, including a higher fundamental frequency $\left(\mathrm{F}_{0}\right)$, longer latency to cry, and shorter overall durations of crying [48;99;100]. As such, these measures of infant crying have been used in the identification of infants at risk for poor neurobehavioral, social and cognitive development [55;99]. While physioacoustic models of infant crying have described the role of coordinated activity among brainstem, midbrain and limbic systems in the production of these and other variations in human infant cry characteristics $[31 ; 54 ; 69 ; 76]$, a paucity of research has explored their neurobiological bases. The analysis of rat pup ultrasonic vocalizations (USVs) may provide a valuable animal model by which the neurobiological basis of variations in the cry sound can be studied. Recent translational analyses suggest that the cry sounds of human infants may have comparable measures in the distress vocalizations of several mammalian species, including the USVs of rat pups [101]. Analyses of rodent vocalizations mirror clinical studies which show human infant cries are similarly age- and context-dependent $[8 ; 82 ; 84 ; 85]$. Neonatal rodent offspring in isolation emit infant $40 \mathrm{kHz}$ distress calls, whereas older rodents emit $22 \mathrm{kHz}$ calls in similar aversive conditions [10;12]. Variations in rodent infant vocalizations are associated with different contextual conditions, such as size of the litter [35], suggested to be related to variations in maternal care individual pups receive in a small litter versus a large litter. It has also been shown that juvenile stress alters adult rodent vocalizations, including potentiation of $22 \mathrm{kHz}$ USVs [98].

While studies of adult rodents indicate that specific brain regions are involved in the control, elicitation, and complexity of experience-dependent vocalizations [16;22;32;34], the neurobiology underlying variations in vocalizations during early development has not been explored in a high-risk rodent model. Preclinical animal studies support the hypothesis that maturation of specific brain regions involved in adult vocalizing behavior, i.e. the amygdala [53;62], ventral medial hypothalamus (VMH) [11], and periaqueductal gray (PAG) $[15 ; 17 ; 42 ; 61]$ are associated with typical developmental changes in offspring behavior, including emergence of fear-like behavior [67;93] and behavioral sex-differences [52]. Whether differential development of these regions contributes to variations in neonatal vocalizations is unknown. One way to address this issue is to examine the effects of prenatal cocaine exposure (PCE) and/or other prenatal stressors on the acoustic characteristics of rat pup USVs, and their relationship to development of specific neural regions. PCE and other stressors have been associated with variations in human infant cry sounds including decreased number of cry expirations and increased amplitude, duration, and fundamental frequency of expirations [19;56;57]. However, mixed results following PCE have been reported in several studies [25;45] potentially related to age at time of cry elicitation, amount or time of drug exposure during pregnancy, and/or other risk factors.

The present study investigated whether PCE is associated with normal developmental changes in USVs in male and female rat offspring at three different age groups corresponding to neonate (designated as postnatal day (PND) 1), infant (PND 14), and early juvenile (PND 21) periods. Neuronal development in the dorsal (dPAG) and ventral PAG (vPAG) on PND 1 (before emotional control of USVs start), and additionally in the central 
(CeA) and basal lateral (BLA) amygdala and also the VMH on PNDs 14 and 21 (to correlate with emergence of "emotional-dependent" USVs) were measured and correlated with variations in vocalizations. We hypothesized that delayed PAG maturation would be associated with decreased number of USVs on PND 1 while delayed CeA and VMH maturation would coincide with increased number of USVs and a lower percentage of 22 $\mathrm{kHz}$ USVs on PND 21 in cocaine-exposed offspring.

\section{Materials and Methods}

\subsection{Animals}

Following a one-week habituation period, virgin female (200-240 grams) Sprague-Dawley rats (Charles River, Raleigh, NC) were placed with males on a breeding rack until a sperm plug was found, which was designated as gestation day (GD) zero. Subjects were randomly assigned to one of three treatment or control groups and singly housed and maintained on a reversed 12:12 reverse light cycle (lights off at 0900 hours) for seven days. They were then transferred to a room with a regular light cycle (lights on at 0700 hours) for the remainder of the experiment, a procedure that generally results in the majority of dams delivering their litters during daylight hours [64]. All procedures were conducted under federal and institutional animal care and use committee guidelines for humane treatment of laboratory subjects.

\subsection{Treatment}

Treatment groups included: chronic cocaine (CC), and two control groups, chronic saline (CS), and untreated (UN) dams. CC and CS dams received subcutaneous (SC) injections on alternating flanks of $15 \mathrm{mg} / \mathrm{kg}$ cocaine HCL (dose calculated as the free base, Sigma Chemical Company, St. Louis, MO) dissolved in $0.9 \%$ normal saline (total volume $2 \mathrm{ml} / \mathrm{kg}$ ), or the same volume of normal saline $(0.9 \%)$, respectively. Injections were delivered twice daily (at approximately 0800 and 1600 hours) throughout gestation beginning on GD 1 and continuing until the day before delivery (GD 1-20) with the CS dams serving as controls for injection and nutritional stress. UN dams were weighed and handled daily, but received no drug treatment. CC and UN dams had free access to water and food (rat chow), while CStreated dams were yoke-fed over the first week to match maximum consumption rates of CC dams to control for the anorectic effects of cocaine, as previously described [38;40]. To investigate neuronal postnatal development in offspring, pregnant dams from all three treatment groups received an injection of Bromodeoxyuridine $(\mathrm{BrdU})(10 \mathrm{mg} / \mathrm{kg})$ between 0800 and 0900 hours, before any other injections or handling, for three consecutive days (GDs 13-15). These three consecutive days were chosen based on prior research showing this developmental window is the peak period of neurogenesis for brain regions of interest $[6 ; 7 ; 79 ; 80]$ and pilot staining showing positive BrdU staining in all regions of interest following BrdU administration on these respective days. A small cohort of animals were tested in a pilot study to examine the effects of BrdU on neonatal vocalizations, maternal behavior, and weight gain in all three treatment groups and findings suggested no BrdUrelated differences at the dose employed here (data not shown). While BrdU has been found to have adverse effects on development when administered gestationally [47], the dose we employed is lower than that previously found to have no effect on cellular kinetics [59] and therefore caused no problems in the present study.

\subsection{USV Testing Procedures}

Offspring were left undisturbed with their biological dams for three hours following delivery (designated as PND 1) and then brought to the test room and allowed to habituate to the room for 15 minutes. One male and female offspring were removed from the litter, weighed, and placed together in a plastic holding cage on top of a heating pad for five minutes. At the 
end of five minutes, skin temperature on the rear flank of each offspring was recorded with a laser thermometer (Fischer Scientific, Model 15-077-966). The male and female offspring from each litter were simultaneously placed onto two separate individual cold scales in two Med Associates sound attenuated boxes, each with a Med Associates Ultrasonic Vocalization Detector (model number ANL-937-1) attached to a unidirectional microphone and powered by SG-501 power supply. Med Associate USV detectors scan ultrasonic frequencies every 30 milliseconds and record the amplitude of sound at each frequency between $20 \mathrm{kHz}$ and $100 \mathrm{kHz}$. Detectors are connected to a laptop computer and data acquired and analyzed through ANL-937-1 MED USV Application Software (SOF-937-1) and the "MED-USV.xls" macro for Microsoft excel. USV testing lasted for 5 minutes, and after testing, offspring skin temperature was again recorded. The temperature of the cold scale was measured before and after testing to control for confounding environmental temperature differences using a laser thermometer. Following testing, both offspring had their temperature assessed and were sacrificed and their brains collected for immunohistochemical analysis. The offspring's biological dam and littermates were returned to the animal facility and left undisturbed until the next assigned test days. On PNDs 14 and 21, litters were brought to the testing room and the same PND 1 testing procedure was carried out on another male and female offspring pair.

\subsection{USV Analysis}

Following vocalization testing with ANL-937-1 MED USV Application Software (SOF-937-1), data were loaded and analyzed with the "MED-USV.xls" macro for Microsoft excel. Data output included the amplitude of sound at each frequency between 20 and $100 \mathrm{kHz}$ for every instance that sound exceeded the manually set threshold level of $25 \mathrm{~dB}$. Data output was examined by generated 3-D area graphs, where the $\mathrm{x}$-axis was frequency $(\mathrm{kHz})$, y-axis was amplitude (dB), and z-axis was time (sec). Data was then manually categorized as a USV or other broad spectrum sound (i.e. from offspring movement in the box). To ensure proper categorization, a subset of rodent offspring were tested for USVs simultaneously with the Med Associates Detection software and with a model 4939 microphone connected to (model 2670) preamplifiers, running through a 2-channel model 4939 power amplifier (all Brüel and Kjær), and connected to a computer through a National Instruments instrumentation recorder (779193-01-DAQPad-6015) sampling at a rate of $200 \mathrm{kS} / \mathrm{s}$ (200,000 samples per second). Spectrograms and fast fourier transforms (FFTs) were created every $30 \mathrm{msec}$ and compared to 3-D area graphs from Med Associate data output (which detects sound every $30 \mathrm{msec}$ ) at every time point a USV was occurring to ensure proper categorization of USVs with med associate equipment.

Individual USVs that occurred within 30 milliseconds of one another were considered to be part of the same call. All of the USVs occurring during the five minute test or up to the first 60 USVs were categorized and subsequently analyzed. Acoustic features assessed for each animal included the duration (average, and total) of USVs, the average interval of time between USVs, the latency to emit the first USV, latency to a USV with an observable harmonic, total number of USVs emitted during the test (up to 60), and the percentage of these USVs with at least one harmonic. Based on their peak fundamental frequency $\left(\mathrm{F}_{0}\right.$, the highest point at which $\mathrm{F}_{0}$ occurred within each USV), USVs were categorized as either occurring at $22(20-29 \mathrm{kHz}), 40(30-46 \mathrm{kHz}), 55(47-59 \mathrm{kHz})$, or greater than $60 \mathrm{kHz}$. Percentage of calls emitted at each frequency band was calculated for each pup. If an animal did not emit a USV, its data was only used in the analysis of total number of USVs emitted during the test. Additionally, to assess if differences in amplitude of calling exists amongst groups the loudest USV emitted was identified and the peak $\mathrm{F}_{0}$ and the amplitude at the peak $\mathrm{F}_{0}$ were recorded for each offspring. 


\subsection{Tissue Fixation and Sectioning}

All PND 1 tissue was paraffin-embedded following a previously established protocol [23]. Based on the tissue consistency of the rodent brain on PND 1, we found that paraffin embedding was the best choice for maintaining tissue integrity through the length of the study. Immediately following vocalization testing, brains were removed and drop-fixed in $4 \%$ paraformaldehyde in $0.1 \mathrm{M}$ phosphate-buffered saline (PBS) for 48 hours followed by two overnight $(\mathrm{O} / \mathrm{N})$ rinses in PBS. Specimens were dehydrated through a graded series of alcohols, cleared with two washes of toluene, and finally embedded in molten paraffin. The embedded specimens were serially sectioned at 10um and immediately mounted to slides and stored at room temperature until immunohistochemistry was performed. Conversely, immediately following USV testing on PND 14 and 21 offspring were deeply anesthetized with pentobarbital $(60 \mathrm{mg} / \mathrm{kg}, 10 \mathrm{ml} / \mathrm{kg}$, i.p.) and perfused transcardially with $0.1 \mathrm{M}$ PBS followed by $4 \%$ paraformaldehyde in PBS. The brains were removed from the skull and placed in the same fixative solution for at least 24 hours before being washed with PBS and sliced on a Leica VT $1000 \mathrm{~S}$ vibrating microtome into 50 um sections. The free-floating sections were stored in cryoprotectant at $-20 \mathrm{C}$ until immunohistochemistry was performed.

\subsection{Immunofluorescence}

For PND 14 and 21 tissue, free-floating sections were picked from each animal for the CeA and BLA (bregma -2.12 to $-2.80 \mathrm{~mm}$ ), VMH (bregma -2.30 to -3.60 ), and the $\mathrm{APAG}$ and vPAG (bregma -6.72 to -7.80 ). Fluorescent immunohistochemistry was adopted from previously described methods [70;87]. The colocalization of BrdU with neuronal-specific nuclear protein $(\mathrm{NeuN})$ was used to characterize the expression of surviving neural precursor cells that were labeled during BrdU injections on the mornings of GDs 13-15. Immunofluorescent assays were conducted as follows: free-floating tissue was washed in PBS, and then treated with $0.6 \%$ hydrogen peroxide to block endogenous peroxidase activity. Next, tissue was incubated in $50 \%$ formamide/2X SSC for thirty minutes at room temperature, then in $2 \mathrm{~N} \mathrm{HCl}$ for one hour at $37^{\circ} \mathrm{C}$. After neutralizing in $0.1 \mathrm{M}$ boric acid, tissue was rinsed in PBS, and incubated in a blocking solution (3\% goat serum, $0.2 \%$ Triton$\mathrm{X}, 0.1 \mathrm{M}$ PBS) for one hour. Tissue was then incubated in a solution containing primary antibodies (1: 400 rat anti-BrdU, Accurate, Westbury, NY, 1:1000 mouse anti-NeuN, Santa Cruz, CA). Antibody dilutions were chosen based on dilution curves and antibody specificity verified in all immunohistochemical assays. The following day, sections were rinsed in PBS, and then incubated in the dark with fluorescent-coupled secondary antibodies appropriate for each primary antibody (Invitrogen, CA) for one hour. Tissue was then rinsed in PBS, mounted onto slides and cover-slipped with Fluoromount-G ${ }^{\mathrm{TM}}$ (Southern Biotech, Birmingham, AL), taking care to protect the sections from the light.

Sections selected for analysis from the PND 1 age group contained the PAG region of interest (coronal plate 19-20 in embryonic day 22 rodent offspring as cited in Atlas of Prenatal Rat Brain Development [3]). Sections selected were deparaffinized with xylene, rehydrated through a graded alcohol series, and quenched using $5 \% \mathrm{H}_{2} \mathrm{O}_{2}$ in methanol. Steam antigen retrieval was performed using a citrate buffer (Antigen Retrieval Citra, BioGenex, San Ramon, CA). DNA was denatured with $2 \mathrm{~N} \mathrm{HCl}$ for one hour at $37 \mathrm{C}$, neutralized with $0.1 \mathrm{M}$ Borate Buffer, and then incubated with blocking solution (3\% goat serum, $0.2 \%$ Triton-X, $0.1 \mathrm{M}$ PBS) before incubation in primary antibodies. Primary antibodies consisted of mouse anti- NeuN (Santa Cruz, CA, 1:1000) and rat anti-BrdU (Accurate Chemical and Scientific Corp., NY, dilution 1:400). The following day, slides were rinsed in PBS, and then incubated in the dark with fluorescent-coupled secondary antibodies appropriate for each primary antibody (Invitrogen, CA). Slides were rinsed in PBS and cover-slipped using Fluoromount-G ${ }^{\mathrm{TM}}$ (Southern Biotech, Birmingham, AL). Protein expression at PND 1 was only assessed in the PAG since studies assert that 
vocalizations at this neonatal age are not emotionally based, but controlled by brain stem mechanisms [66].

\subsection{Visualization and Analysis of Immunofluorescence}

Double-label immunofluorescence was visualized with a Leica SP2000 confocal scanning microscope with a 40X oil objective. Anatomy hallmarks for each region were employed to ensure consistent imaging during microscopy. Co-localization was confirmed by confocal microscopy optimized for the analysis of tissue sections. For each subject, images were acquired from the left and right hemisphere from a minimum of four tissue sections for each brain region. Image analysis was adapted from previously described methods [14]. In brief, optimal thresholds for NeuN and BrdU/NeuN co-localization was identified for each age group and kept constant for all subjects. Total number of nuclei stained was assessed using the plug-in for nucleus detection in Image $\mathbf{J}$ for microscopy.

\subsection{Statistical Analysis}

A one-way ANOVA for treatment group was used to examine the effects of PCE on gestational and postnatal litter data. Fisher LSD post hoc tests were conducted to find the differences between the three treatment groups. A 2 (sex) by 3 (treatment group) ANOVA was conducted for measures of offspring weight and temperature for each respective test day. Because groups differed in the number of offspring emitting vocalizations on each test day Kruskal-Wallis tests (for continuous results) or Fisher's exact test (for binary questions such as if offspring emitted a vocalization or not) were used to assess treatment group differences. Conover-Inman tests for all pair wise comparisons were conducted to evaluate which treatment groups were different from each other. Wilcoxon signed rank test (paired for continuous results) or McNemar's test (for binary results) were also used for evaluating sex differences by day and treatment group.

A 2 (sex) by 3 (treatment group) ANOVA was conducted for each brain region at each age group on measures of total NeuN-positive labeled cells and the percentage of BrdU-positive cells that co-labeled as a NeuN-positive neuron. Following overall significance Fisher LSD post-hoc tests were conducted to find the differences between the three treatment groups. Pearson product-moment correlations were employed to examine the relationship between rodent vocalizations and development of different brain regions. These measures include the total number of NeuN-positive cells and the percentage of BrdU-positive cells that colabeled as a mature NeuN-positive neuron at each respective age. Animals that did not emit at least one USV were only included in correlations with total number of USVs.

\section{Results}

\subsection{Gestational/ Litter Data}

Results of the one-way ANOVA for treatment group showed a significant main effect in gestational weight gain of dams $(\mathrm{F}=4.158, \mathrm{p} \unlhd 0.05)$, specifically $\mathrm{CC}$ dams $(\mathrm{n}=11)$ gained less weight across the gestational period than did UN dams (Fisher, $\mathrm{p} \unlhd$ ).01). There were no differences between CS dams $(n=10)$ and UN dams $(n=11)$ on this measure. CC dams also gained more weight between postpartum days (PPDs) 1-21 (ANOVA, F=4.305, p 40.05 ) than did UN (Fisher HSD, p $\$$ ).01) but not CS dams. By PND 21, there were no significant differences in weight between treatment groups. There were no group differences in litter size or sex ratio, litter birth weight, culled litter weight, or the culled litter weight gain from birth to PND 21. Group offspring weights on PND 1, 14, or 21 were not significantly different. Results of the one way ANOVA showed a significant treatment group effect ( $\mathrm{F}=3.087, \mathrm{p} \unlhd$.05) on offspring temperature on PND 1 before vocalization testing, such that PCE offspring were warmer than CS offspring (Fisher, $\mathrm{p} \ \mathbf{4 0 5}$ ), and had a trend for being 
warmer than UN offspring (Fisher, p $₫$ (0.09) with no differences following testing cessation. There were no group differences in temperature measures at any measurement time on either PND 14 or 21 and the plate temperatures were the same for all tests.

\subsection{Developmental Variations in Vocalizations}

3.2.1. PND 1 Vocalizations-PCE decreased vocalizations in both PND 1 male and female offspring in a sex and temperature dependent manner. Based on high variability of the data and body temperature differences observed in PCE offspring, a linear mixed model was used to evaluate sex and treatment group effects adjusted for starting temperature and weight of offspring. We found that variability in the total number of USVs emitted could be explained in part by temperature of the offspring. A higher body temperature at time of testing was directly related to a higher total number of USVs ( $\mathrm{p} \unlhd$ ).05), while offspring weight did not show this association $(\mathrm{p}=0.8232)$. After adjusting for body temperature, there was a significant main effect of group for total number of USVs emitted ( $\mathrm{p} \unlhd .05$ ), with both male and female PCE offspring vocalizing less overall compared to CS (p \).01) and UN offspring ( $\mathrm{p}=0.06$, Figure $1 \mathrm{~A}$ ) with no significant difference in the total duration of vocalizations (Figure 1B). Starting temperature and weight were not associated with any other acoustic measures.

There was a treatment effect for PND 1 males on the percentage of calls that had at least one observable harmonic $(Z=7.633 ; p \unlhd 0.05$, Figure 1C) and on the latency to emit a USV with at least one observable harmonic ( $\mathrm{Z}=5.852 ; \mathrm{p} \unlhd$.05). PND 1 PCE males produced a smaller percentage of calls with a harmonic compared to UN (Conover Inman, p $₫$ ).005) and CS (Conover Inman, $\mathrm{p}=0.059$ ) males; and a longer latency to emit a USV containing a harmonic than both UN and CS male offspring (Conover Inman, p $₫ .05$ ). No other significant differences in vocalizations were observed on PND 1.

3.2.2. PND 14 Vocalizations-There were no significant treatment or sex group differences in vocalizations of offspring on PND 14 (See Figure 1 A-E).

3.2.3. PND 21 Vocalizations-PCE and CS exposure were associated with vocalization differences on PND 21 in a sex-dependent manner.

3.2.3.1. Males: There were no significant treatment effects in the total number of USVs on PND 21 (Figure 1A), but there was a main effect (Kruskal-Wallis) of treatment group for males in the total duration of USVs $(Z=6.157 ; \mathrm{p} \unlhd .05$, Figure 1B), the minimum interval between USVs observed ( $Z=7.528 ; \mathrm{p} \unlhd 0.05$ ), and the amplitude of the loudest call measured $(Z=9.268 ; p \unlhd$ s.01, Figure 1D). PCE and CS males vocalized longer (total duration-Conover Inman, $\mathrm{p} \unlhd .05$ ); cried at a higher amplitude at the loudest call emitted (Conover Inman, PCE $\mathrm{p} \unlhd 0.05$, CS $\mathrm{p} \unlhd .005$ ) and had a smaller minimum interval between USVs (Conover Inman, PCE $\mathrm{p} \unlhd 0.05$, CS $\mathrm{p} \unlhd$ \.01) than did UN males on PND 21. There were no differences in the percentage of USVs that had a harmonic (See Figure 1C) or other vocalization measures between male offspring.

3.2.3.2. Females: There was a main effect of treatment group in the percentage of USVs emitted that fell into the $22 \mathrm{kHz}$ range ( $\mathrm{Z}=9.720 ; \mathrm{p} \unlhd(.01$, See Figure 1E) in female offspring. CS (Conover Inman, p $₫$ 0.005) and PCE females (Conover Inman, p $₫$.05) emitted fewer 22kHz USVs compared to UN females on PND 21.

3.2.3.3. Within Group Sex Effects: PCE and CS exposure was associated with USV sex differences on PND 21 that were not observed in UN offspring. Wilcoxon signed rank tests indicated that PCE males $(n=10)$ emitted a greater total number of USVs ( $p \unlhd$.05, Figure 
1A), a longer total duration of USVs ( $\mathrm{p} \unlhd .05$, Figure 1B), and had a greater percentage of USVs that fell into the $55 \mathrm{kHz}$ range compared to PCE females ( $\mathrm{n}=10, \mathrm{p} \unlhd .05$, not shown). CS males $(n=10)$ had a shorter average interval between calls ( $\mathrm{p} \triangle 1.05)$ and a greater amplitude of the loudest call emitted compared to CS females ( $n=10, p \unlhd 0.05$ ). The only within group sex effect observed for UN offspring was that $\mathrm{UN}$ males $(\mathrm{n}=11)$ had a shorter latency to emit the first USV compared to UN females ( $n=11, p \unlhd 0.05$ ).

\subsection{Developmental Variations in Limbic Regions of Interest}

3.3.1. PND 1 IHC Cell Counts-There were no group effects associated with dPAG developmental changes on PND 1. There was however a main effect in the percentage of BrdU cells that co-labeled as a NeuN-positive neuron in the vPAG on PND 1 (ANOVA, $\mathrm{F}=3.808, \mathrm{p} \unlhd .05$, not shown), showing that $\mathrm{CS}$ offspring had a significantly greater percentage of BrdU cells that co-labeled as a NeuN-positive neuron in the vPAG compared to UN (Fisher LSD, $p$ \).01) but not PCE offspring. There were no other developmental differences observed in the PAG on PND 1.

3.3.2. PND 14 IHC Cell Counts-PCE and CS exposure was differentially associated with sex-dependent developmental differences in the CeA and vPAG but not in the BLA, $\mathrm{VMH}$, or dPAG.

3.3.2.1. NeuN-positive Cell: There was a group by sex interaction (ANOVA, $F=5.387$, $\mathrm{p} \unlhd \mathbf{0 . 0 1}$, See Figure 2A) in the total number of NeuN-positive neurons in the CeA on PND 14. PCE females had less NeuN-positive cells compared to UN females (Fisher LSD, p $₫$ (0.01) and PCE males (Fisher LSD, p $₫$ (0.05). CS males also had significantly fewer NeuNpositive cells compared to PCE males (Fisher LSD, p $₫$.05), and both CS (Fisher LSD, $\mathrm{p} \unlhd$ (0.05), and UN females (Fisher LSD, p $\unlhd$ ).005).

3.3.2.2. BrdU positive cells co-labeled as NeuN-positive Neurons: There was a group by sex interaction (ANOVA, $\mathrm{F}=3.945, \mathrm{p} \unlhd .05$ ) for the percentage of BrdU-positive cells that co-labeled as a NeuN-positive neuron in the CeA. PCE males had a larger percentage of BrdU cells that co-labeled as a NeuN-positive neuron compared to PCE females (Fisher, $\mathrm{p} \unlhd$ (0.05) and CS males (Fisher, $\mathrm{p} \unlhd$ (0.05). There were no other significant differences in the $\mathrm{CeA}$ or any other regions assessed on PND 14.

3.3.3. PND 21 IHC Cell Counts-Developmental differences previously observed in the CeA on PND 14 normalized in PCE and CS offspring by PND 21 (See Figure 2A,B), however, sex-dependent differences began to emerge in the VMH (See Figures 2B) in PCE and CS offspring.

3.3.3.1. NeuN-positive Cells: As seen in Figures 2B, there was a significant treatment group by sex interaction in total number of NeuN-positive neurons in the VMH on PND 21 (ANOVA, $\mathrm{F}=3.120, \mathrm{p} \unlhd \mathbf{0} .05$ ). PCE males had a greater density of mature neurons in the VMH on PND 21 than PCE females, CS females, and UN males (Fisher, $\mathrm{p} \unlhd$ ().05). CS males also had more NeuN-positive neurons in the VMH than CS females (Fisher, $\mathrm{p} \unlhd$ ).05).

3.3.3.2. BrdU positive cells co-labeled as NeuN-positive Neurons: There were no significant differences in the percentage of BrdU positive cells that co-labeled as a NeuNpositive neuron on PND 21 in any brain regions assessed.

\subsection{Correlations Between Variations in Vocalizations and Limbic Region Development}

3.4.1. PND 1 Vocalizations and Regional Development Correlations-There were no significant correlations between the dPAG or the vPAG in total number of NeuN-positive 
cells or percentage of BrdU-positive cells that co-label as a NeuN-positive neuron with variations in rodent offspring vocalizations on PND 1.

\subsubsection{PND 14 Vocalizations and Regional Development Correlations-By PND}

14 , some acoustic measures of vocalizations began to correlate with VMH developmental differences (not shown). A significant inverse relationship was observed for the percentage of BrdU cells that co-label as a mature neuron in the VMH and the amplitude of the loudest call produced ( $r=-0.398, \mathrm{p} \unlhd$ (0.005). Specifically, a greater percentage of BrdU cells that colabeled as a neuron in the VMH correlated with a lower amplitude of the loudest call. There were no other relationships between PND 14 rodent offspring vocalizations and total number of NeuN positive cells or percent of BrdU positive cells that co-label as a NeuN positive neuron in any other brain regions.

\subsubsection{PND 21 Vocalizations and Regional Development Correlations-}

Correlations between vocalization acoustic measures and specific brain region developmental differences, specifically the VMH and CeA, began to emerge by PND 21 . The total number of NeuN-positive neurons in the VMH correlated positively with the total duration of USVs ( $\mathrm{r}=0.452, \mathrm{p} \unlhd$ (0).001, Figure $3 \mathrm{~A}$ ) and the amplitude of the loudest USV $(\mathrm{r}=0.495, \mathrm{p} \triangle 0.0005$, Figure 3B). Interestingly, the total number of NeuN-positive neurons in the VMH ( $r=-0.287, \mathrm{p} \unlhd) .05$, Figure $3 \mathrm{C})$ and in the CeA ( $r=-0.274, \mathrm{p} \unlhd .05$, Figure 3D) were inversely related to the percentage of calls that fell into the $22 \mathrm{kHz}$ USV range.

The percentage of BrdU cells that were NeuN-positive neurons in the VMH were positively related to the amplitude of the loudest call $(\mathrm{r}=0.315, \mathrm{p} \unlhd .05)$ and the percentage of BrdU cells that co-labeled as NeuN-positive neurons in the VMH was also inversely related to the percentage of calls that were categorized as a $22 \mathrm{kHz}$ USV ( $r=-0.271, \mathrm{p} \unlhd 0.05$ ). To ensure correlations were not a false positive based on a large number of offspring not emitting any vocalizations in the $22 \mathrm{kHz}$ range and potentially skewing the data correlations were re-ran for only those offspring that emitted at least one $22 \mathrm{kHz}$ USV. Correlations between the number of $22 \mathrm{kHz}$ USVs offspring emitted and either the VMH or CeA developmental measures became more significant (VMH: total NeuN negatively correlated with percentage of USVs that fell in the $22 \mathrm{kHz}$ range $\mathrm{r}=-0.527, \mathrm{p} \unlhd .05$; VMH: Percent of BrdU cells colabeling with NeuN negatively correlated with percentage of USVs that fell in the $22 \mathrm{kHz}$ range $r=-0.692, p \unlhd 005$; CeA: total NeuN negatively correlated with percentage of USVs that fell in the $22 \mathrm{kHz}$ range $\mathrm{r}=-0.589, \mathrm{p} \unlhd(.01)$.

\section{Discussion}

We predicted that PCE would coincide with age- and sex-dependent variations in USVs, limbic circuitry development, and that differences in vocalizations would correlate with variations in development of limbic brain regions. As hypothesized, cocaine-induced changes in neonatal vocalizations were sex and age-dependent. On PND 1, PCE decreased the number of vocalizations in both males and female offspring and PCE males had a smaller percentage of calls with at least one observable harmonic than did UN males at this age. CS exposure did not coincide with differences in vocalizations suggesting that variations observed following PCE can be attributed directly to PCE versus indirectly through stress-related mechanisms. These findings on PND 1 are interesting in light of studies showing maternal substance abuse is associated with neglect in humans [58] and rodents [40;68] perhaps partially mediated through variations in infant cues [38]. In the animal model employed in this study it was previously shown that gestational cocaineexposure alters maternal behavior (with the greatest deficits occurring around PPD 1) and that all rodent mothers or dams (regardless of treatment history) displayed altered maternal behavior towards PCE pups [38] suggesting that some attribute of the PCE pups may render 
them less able to elicit normal maternal care. Variations in vocalizations, including rate of vocalizations and harmonics, could potentially be important cues impacting rodent pup early care. Rodent pup USVs play an important role in altering both the neurobiology and response of the dam $[13 ; 27 ; 28 ; 86]$. Sustained high-rate vocalizations emitted by pups have been shown to be most effective for eliciting retrieval from dams [13;27;103]. While no study to our knowledge has explored the impact of harmonics on early dam-pup interactions in a rodent model it has been shown that following a painful experience, human infants emit cries with indistinct harmonic segments which are then perceived to be more urgent by their environment [77]. It is reasonable to suggest that decreased rate of USVs observed in PCE pups and decreased percentage of calls with a harmonic observed in PCE male pups could be differentially affecting the care taking environment. Current studies are now targeting early translational behavioral differences in PCE pups and their impact on the maternal environment to continue elucidating the mechanisms underlying neglect.

Differences in vocalizations observed on PND 1 normalized by PND 14 in PCE offspring. PND 14 was found to be a peak vocalizing period for all offspring, as evidence in more vocalizations that were longer, louder, and had shorter intervals between individual USVs than at other ages. PND 14 in rodents is thought to be roughly equivalent in age to one month old human infants who have a peak crying period around six to eight weeks [5] followed by a decrease in rate of crying [78]. Rodent infants show a similar developmental shift to human infants, as rates of isolation-induced USVs increase during the early postnatal period and peak in rate between the first and second week of postnatal life [36;37;83]. This peak is subsequently followed by a decrease in rate of USVs as signs of fear-like behavior emerge (i.e. freezing) when the offspring is in an aversive environment (i.e. predator odor or isolation) [44]. Our age comparisons support this developmental progression in rodent infants.

Interestingly, we found that by PND 21 PCE and CS-exposure in males prolonged higher rates of vocalizations that were louder with shorter intervals between USVs. While human PCE has been suggested to decrease neonatal crying [19] similar to what we observed on PND 1, it has also been found to increase excessive crying and irritability [25;45]. In general, "excessive crying" has been referred to as a common symptom following substance exposure [29]. Since prenatal stress has also been suggested to result in excessive crying [90] with a peak period of fussiness occurring between three and six months of age [95], similar findings in both PCE and CS males could suggest effects at this age may reflect a common or similar early developmental stress effect or similar developmental mechanisms are targeted by prenatal stress and cocaine. Variations in vocalizations were sex specific suggesting that males may be more sensitive to these manipulations which support previous reports. Sex-dependent differences in rats have been reported for a number of measures following PCE $[21 ; 33 ; 39 ; 60]$ and prenatal stress [4] with males suggested to be more vulnerable to prenatal complications, including stress [30]. These findings are particularly interesting in light of the many neurodevelopmental disorders (many with increased prevalence in males) that are associated with altered early communication in humans. For instance, parents of children with autism spectrum disorder often report that they cannot understand why their child is crying in the first year. These parents describe their child's cries as unexpected and loud [24]. Altered crying behavior in males could also have a detrimental impact on the maternal environment, especially in populations more vulnerable to neglect-like behavior such as those abusing cocaine. These considerations further strengthen the need for more research exploring the implications of sex-dependent changes in vocalizations.

The present study also explored the neural mechanism(s) underlying variations in vocalizations at each respective age. Cocaine has been shown to consistently decrease adult 
neurogenesis [20;71;97], however, research has yet to provide a systematic evaluation of neuronal development following PCE or if neuronal developmental deficits normalize during the neonatal period and the impact these changes have on behavior in PCE offspring. To begin addressing this we examined the PAG, amygdala, and VMH for developmental differences between PCE, CS, and UN rodent offspring. PCE wasn't associated with variations in PAG development on PND 1 but by PND 14 PCE was differentially associated with variations in brain development in male and female offspring. PCE in females was associated with decreased neuronal density in the CeA while PCE in males was associated with increased neuronal differentiation (a larger percentage of BrdU cells that colabeled as a NeuN-positive neuron). Variations in CeA development observed on PND 14 were found to have normalized by PND 21 while variations in VMH development began to emerge in PCE males. PCE in males was associated with increased neuronal density in the VMH on PND 21. We were surprised that PCE in males was associated with increased neuronal differentiation in the CeA (PND 14) and increased neuronal density in the VMH (PND 21) as we hypothesized that they PCE would coincide with delayed neuronal maturation (i.e. decreased number of neurons). PCE has previously been shown to decrease proliferation but not effect cell survival [50], increase apoptosis in the fetal brain [96], disrupt migration, and/ or enhance differentiation in offspring [51]. Neuronal differentiation/ neurogenesis on PND 21 has previously been found to be differentially affected in male and female rodent offspring following one day of maternal deprivation on PND three. Specifically, maternal deprivation enhances neuronal differentiation in males yet decreases neuronal differentiation in females [74]. Based on these findings differential variations in brain development in PCE male and female offspring could be more directly related to environmental differences occurring in the neonatal environment. CS-exposure in male offspring also increased neuronal density in the VMH on PND 21 suggesting that results are more related to general stress mechanisms or that environmental differences (occurring in both the PCE and CS environment) could be more related to changes in VMH development. Similar results in both the PCE and CS males on PND 21 are very interesting and require more work to elucidate the relevance of findings. Differential age related results are not surprising as the neonatal period is very dynamic with behavior and brain development changing rapidly. It has previously been shown that prenatal stress differentially affects amygdala development depending on the age of examination (with PND 25 showing the most robust differences as compared to PND 7, 45, or 60) suggesting this juvenile period might be a particularly sensitive time in development [46]. It is also important to note that cell death continues to occur in the brain through adolescence and is also sexually dimorphic [72;73]. However, since PND 21 PCE and CS males showed significantly greater neuronal density in the VMH but did not show a significant difference in the percentage of BrdU-positive cells that colabeled as a NeuN-positive neuron results can be interpreted as a consequence of more immature neurons differentiating/ maturing sooner verses dysregulated apoptosis as survival of BrdU-positive cells was not affected. Future studies are needed to clarify the mechanism(s) underlying findings, i.e. if results are a consequence of altered differentiation or dysregulated apoptosis.

Understanding the behavioral implications of altered limbic system development could have strong implications for early intervention in the clinical setting. We hypothesized that variation in PAG development, a region critical for triggering vocalizations [43;49] in response to both emotional $[1 ; 102]$ and somatosensory input [65;81], would impact vocalization production, even during the very early neonatal period when vocalizations are speculated to be an acoustic by-product of changes in internal homeostasis (i.e. thermoregulation, pain) and not emotionally or cognitively produced [9]. Variations in vocalizations between PCE and control offspring did not however correlate with altered PAG development on PND 1. While CS-exposure was associated with developmental differences in the vPAG these differences did not correlate with variations in vocalizations. 
Future studies are needed to clarify the functional implications of these changes. Future studies targeting later proliferation times (i.e. GDs 16-17) might help to clarify findings as proliferation in the PAG occurs between GDs 13-17 in a ventral to dorsal gradient [2]. Since neonatal vocalizations are thought to be produced via a 'brainstem model' in that regions rostral to the midbrain are not required for vocalization production during early infant development [69], perhaps other regional changes in the brainstem such as the nucleus ambiguous [92], should be explored in PCE offspring.

We also hypothesized that by PND 21 developmental differences in limbic "fear-related" circuitry would correlate with variations in vocalizations, including increased rates of vocalizations and delayed onset of $22 \mathrm{kHz}$ USVs. In the present study PCE and CS female (significant) and male (non-significant) offspring had a reduction in the percentage of USVs that fell into the $22 \mathrm{kHz}$ range on PND 21 suggesting that both PCE and CS exposure may alter emergence of USV expression associated with fear-like behavior though this effect was stronger in females. As the limbic system matures in the developing human infant the first displays of fear-like behavior begin to emerge [34]. Previous animal studies indicate that fear-like behavior is associated with plasticity of the VMH [75] and amygdala [18;88]. Our findings support this in that greater neuronal density in the $\mathrm{VMH}$ and $\mathrm{CeA}$ negatively correlated with the percentage of $22 \mathrm{kHz}$ USVs emitted, suggesting a role for both the CeA and $\mathrm{VMH}$ in the model employed in this study with behavioral findings of delayed onset of fear-like behavior which should be further explored. We also found increased neuronal density in the VMH on PND 21 (and larger percentage of BrdU cells co-labeled as a neuron) positively correlated with the total duration of vocalizations suggesting dysregulated VMH development (previously suggested as playing a role in infant crying [41]), may possibly have contributed to altered vocalizations in PCE and CS males. It is important to note that data appears to be bi-modal for many acoustic measures. Fear circuitry has recently been shown to be modulated by the medial prefrontal cortex [16] and hence other regions could be playing a role in vocalization production and control as offspring appear to fall into two categories: those that vocalize and those that don't suggesting other mechanisms of inhibition are occurring.

Increased amplitude of USVs in PCE and CS males on PND 21 also correlated with variations in VMH development. Stimulation of the VMH has previously been associated with increased USV amplitude parallel to pain-induced increases in USV amplitude [11]. It was interesting that the correlation of VMH with amplitude was age-dependent. PND 14 offspring showed a negative relationship between amplitude and the percentage of BrdU cells that co-labeled as a neuron while PND 21 offspring showed a positive relationship between amplitude and the density of VMH neurons. Defensive behavior and what is perceived as a threatening stimulus changes in an age-dependent manner during early development [93]. Differential age-specific relationship between VMH development and amplitude of calling could represent a developmental change in VMH function or changing sensitivity to the isolation/ cold scale stimulus used for USV elicitation in this study.

Recent findings suggest changes in the amplitude of USVs are associated with early differences in the neonatal environment (i.e. maternal care), and might be functionally relevant as a behavioral marker of early environmental differences [94] further suggesting similar behavioral findings in PCE and CS males may be more related to common environmental differences associated with prenatal stress. With this in mind, it is important to note that a limitation of this study is that we did not differentiate between the consequences of prenatal cocaine or stress-induced changes in offspring vocalizations or brain development with that of differences in the postnatal environment. Previous studies have found that early environmental experience alters vocalizations in rodent pups. Specifically, pups experiencing five days of brief maternal separation/deprivation (an animal 
model of maternal neglect) from PND two through six vocalize less and show subtle changes in the sonographic structure of USVs than control pups when re-isolated from their dam and litter on PNDs seven and twelve [103;104]. Additionally, maternal deprivation has been shown to decrease neurogenesis in the hippocampus [26] and to effect neural proliferation differentially in male and female offspring. Prenatal stress also differentially affects neural proliferation in male and female offspring [63;89;91]. These gender differences are speculated to coincide with behavioral differences in adulthood and imply that early life stress establishes sex differences in neural plasticity, contributing to alterations in the HPA axis [74]. These studies and our findings here might suggest differences in vocalizations and differences observed in the VMH on PND 21 might be primarily related to environmental-induced differences. Future studies employing cross fostering paradigms should focus on determining the role of the postpartum environment as an independent mediator of these effects.

\section{Conclusion}

In conclusion, PCE disrupted offspring vocalizations in an age-dependent fashion with neonatal offspring exhibiting decreased rates of vocalizations and juvenile offspring displaying increased overall rates of vocalizations. While variations in vocalizations on PND 1 appear to be related directly to PCE as CS offspring did not exhibit parallel changes in vocalizations we found that on PND 21 differences observed were in general parallel for PCE and CS offspring suggesting the mechanism(s) underlying these differences in juvenile behavior may be more related to general stress effects experienced in both environments. Males appear to be more sensitive to cocaine and stress-induced changes in vocalizations as juveniles than do females. The impact of variations in neonatal and juvenile cry acoustic properties on the maternal and social environment needs to be further explored. For instance, if human male infants prenatally exposed to cocaine emit expirations that have differential acoustic properties, such as differences in harmonics (as observed on PND 1) or changes in amplitude and overall rates of crying (as observed on PND 21) these variations could influence maternal perception (i.e. feeling of urgency) and hence parental response toward the infant. Data also suggest developmental differences in the VMH and CeA are associated with these variations in vocalizations, supporting previous reports that the cry is both a social and biological signal. Additional research is needed to elucidate how infant behavior and neural development interact with the infant's environment to influence long-term developmental outcomes. Understanding the neural basis of behavioral changes following prenatal insults, commonly found to be correlated with neurodevelopmental disorders, has great promise for discovering early biomarkers and novel interventions.

\section{Acknowledgments}

We would like to acknowledge the invaluable contributions of the UNC Michael Hooker Microscopy Core Facility (especially Dr. Neal Kramarcy), Dr. Hsiao Tien, Dr. Matthew McMurray, Dr. Sarah Williams, Dr. Joan Morrell, and Dave Gardner, for their help in the preparation of this manuscript and data collection as well as their thoughtful discussions with the authors. This project was supported though the National Institute on Drug Abuse by Award Number P01DA022446 (awarded to Josephine M. Johns) and pre-doctoral training grant F31DA030060 (awarded to Elizabeth T. Cox). The content is solely the responsibility of the authors and does not necessarily represent the official views of the National Institute on Drug Abuse or the National Institutes of Health.

\section{Reference List}

1. Adamec RE, Blundell J, Burton P. Phosphorylated cyclic AMP response element binding protein expression induced in the periaqueductal gray by predator stress: its relationship to the stress experience, behavior and limbic neural plasticity. Prog Neuropsychopharmacol Biol Psychiatry. 2003; 27(8):1243-1267. [PubMed: 14659479] 
2. Altman J, Bayer SA. Development of the brain stem in the rat. V. Thymidine-radiographic study of the time of origin of neurons in the midbrain tegmentum. J Comp Neurol. 1981; 198(4):677-716. [PubMed: 7251936]

3. Altman, J.; Bayer, SA. Atlas of Prenatal Rat Brain Development. 2000 Corporate Blvd., N.W., Boca Raton, Florida 33431: CRC Press, Inc.; 1995. p. 572-575.

4. Bale TL. Sex differences in prenatal epigenetic programming of stress pathways. Stress. 2011; 14(4):348-356. [PubMed: 21663536]

5. Barr RG, Chen S, Hopkins B, Westra T. Crying patterns in preterm infants. Dev Med Child Neurol. 1996; 38(4):345-355. [PubMed: 8641539]

6. Bayer, SA.; Altman, J. Neocortical Development. New York: Raven Press; 1991.

7. Bayer SA, Altman J, Russo RJ, Zhang X. Timetables of neurogenesis in the human brain based on experimentally determined patterns in the rat. Neurotoxicology. 1993; 14(1):83-144. [PubMed: 8361683]

8. Blass EM, Camp CA. Changing determinants of crying termination in 6- to 12-week-old human infants. Dev Psychobiol. 2003; 42(3):312-316. [PubMed: 12621657]

9. Blumberg MS, Alberts JR. Ultrasonic vocalizations by rat pups in the cold: an acoustic by-product of laryngeal braking? Behav Neurosci. 1990; 104(5):808-817. [PubMed: 2244987]

10. Blumberg MS, Alberts JR. On the significance of similarities between ultrasonic vocalizations of infant and adult rats. Neurosci Biobehav Rev. 1991; 15(3):383-390. [PubMed: 1956606]

11. Borszcz GS. Contribution of the ventromedial hypothalamus to generation of the affective dimension of pain. Pain. 2006; 123(1-2):155-168. [PubMed: 16564622]

12. Brunelli SA, Nie R, Whipple C, Winiger V, Hofer MA, Zimmerberg B. The effects of selective breeding for infant ultrasonic vocalizations on play behavior in juvenile rats. Physiol Behav. 2006; 87(3):527-536. [PubMed: 16488454]

13. Brunelli SA, Shair HN, Hofer MA. Hypothermic vocalizations of rat pups (Rattus norvegicus) elicit and direct maternal search behavior. J Comp Psychol. 1994; 108(3):298-303. [PubMed: 7924260]

14. Byun J, Verardo MR, Sumengen B, Lewis GP, Manjunath BS, Fisher SK. Automated tool for the detection of cell nuclei in digital microscopic images: application to retinal images. Mol Vis. 2006; 12:949-960. [PubMed: 16943767]

15. Calizo LH, Flanagan-Cato LM. Estrogen-induced dendritic spine elimination on female rat ventromedial hypothalamic neurons that project to the periaqueductal gray. J Comp Neurol. 2002; 447(3):234-248. [PubMed: 11984818]

16. Chan T, Kyere K, Davis BR, Shemyakin A, Kabitzke PA, Shair HN, et al. The role of the medial prefrontal cortex in innate fear regulation in infants, juveniles, and adolescents. J Neurosci. 2011; 31(13):4991-4999. [PubMed: 21451037]

17. Chen YL, Li AH, Yeh TH, Chou AH, Wang HL. Nocistatin and nociceptin exert opposite effects on the excitability of central amygdala nucleus-periaqueductal gray projection neurons. Mol Cell Neurosci. 2009; 40(1):76-88. [PubMed: 18930828]

18. Collins DR. Synthetic versus natural cat odorant effects on rodent behavior and medial amygdala plasticity. Behav Neurosci. 2011; 125(1):124-129. [PubMed: 21319894]

19. Corwin MJ, Lester BM, Sepkoski C, McLaughlin S, Kayne H, Golub HL. Effects of in utero cocaine exposure on newborn acoustical cry characteristics. Pediatrics. 1992; 89(6 Pt 2):11991203. [PubMed: 1594377]

20. Dominguez-Escriba L, Hernandez-Rabaza V, Soriano-Navarro M, Barcia JA, Romero FJ, GarciaVerdugo JM, et al. Chronic cocaine exposure impairs progenitor proliferation but spares survival and maturation of neural precursors in adult rat dentate gyrus. Eur J Neurosci. 2006; 24(2):586594. [PubMed: 16903860]

21. Dow-Edwards D. Sex differences in the effects of cocaine abuse across the life span. Physiol Behav. 2010; 100(3):208-215. [PubMed: 20045010]

22. Dujardin E, Jurgens U. Afferents of vocalization-controlling periaqueductal regions in the squirrel monkey. Brain Res. 2005; 1034(1-2):114-131. [PubMed: 15713263]

23. Dunty WC Jr, Chen SY, Zucker RM, Dehart DB, Sulik KK. Selective vulnerability of embryonic cell populations to ethanol-induced apoptosis: implications for alcohol-related birth defects and 
neurodevelopmental disorder. Alcohol Clin Exp Res. 2001; 25(10):1523-1535. [PubMed: 11696674]

24. Esposito G, Venuti P. Understanding early communication signals in autism: a study of the perception of infants' cry. J Intellect Disabil Res. 2010; 54(3):216-223. [PubMed: 20136681]

25. Eyler FD, Behnke M, Conlon M, Woods NS, Wobie K. Birth outcome from a prospective, matched study of prenatal crack/cocaine use: II. Interactive and dose effects on neurobehavioral assessment. Pediatrics. 1998; 101(2):237-241. [PubMed: 9445497]

26. Fabricius K, Wortwein G, Pakkenberg B. The impact of maternal separation on adult mouse behaviour and on the total neuron number in the mouse hippocampus. Brain Struct Funct. 2008; 212(5):403-416. [PubMed: 18200448]

27. Farrell WJ, Alberts JR. Maternal responsiveness to infant Norway rat (Rattus norvegicus) ultrasonic vocalizations during the maternal behavior cycle and after steroid and experiential induction regimens. J Comp Psychol. 2002; 116(3):286-296. [PubMed: 12234079]

28. Farrell WJ, Alberts JR. Stimulus control of maternal responsiveness to Norway rat (Rattus norvegicus) pup ultrasonic vocalizations. J Comp Psychol. 2002; 116(3):297-307. [PubMed: 12234080]

29. Galanter, M.; Kleber, HD. The american psychiatric publishing textbook of substance abuse treatment 4th edition. Arlington, VA: American Psychiatry Publishing, Inc.; 2008.

30. Gerardin P, Wendland J, Bodeau N, Galin A, Bialobos S, Tordjman S, et al. Depression during pregnancy: is the developmental impact earlier in boys? A prospective case-control study. J Clin Psychiatry. 2011; 72(3):378-387. [PubMed: 21208585]

31. Golub, HL.; Corwin, MJ. A physioacoustic model of the infant cry. In: Lester, BM.; Boukydis, CFZ., editors. Infant Crying: Theoretical and Research Perspectives. New York: Plenum; 1985. p. 59-82.

32. Gonzalez-Lima F, Frysztak RJ. Functional mapping of the rat brain during vocalizations: a 2deoxyglucose study. Neurosci Lett. 1991; 124(1):74-78. [PubMed: 1857547]

33. Hamilton LR, Czoty PW, Nader MA. Behavioral characterization of adult male and female rhesus monkeys exposed to cocaine throughout gestation. Psychopharmacology (Berl). 2011; 213(4): 799-808. [PubMed: 20959969]

34. Herschkowitz N, Kagan J, Zilles K. Neurobiological bases of behavioral development in the first year. Neuropediatrics. 1997; 28(6):296-306. [PubMed: 9453026]

35. Hofer MA, Brunelli SA, Shair HN. The effects of 24-hr maternal separation and of litter-size reduction on the isolation-distress response of 12-day-old rat pups. Dev Psychobiol. 1993; 26(8): 483-497. [PubMed: 8293894]

36. Hofer MA, Masmela JR, Brunelli SA, Shair HN. The ontogeny of maternal potentiation of the infant rats' isolation call. Dev Psychobiol. 1998; 33(3):189-201. [PubMed: 9810471]

37. Hofer MA, Shair H. Sensory processes in the control of isolation-induced ultrasonic vocalization by 2-week-old rats. J Comp Physiol Psychol. 1980; 94(2):271-279. [PubMed: 7364999]

38. Johns JM, Elliott DL, Hofler VE, Joyner PW, McMurray MS, Jarrett TM, et al. Cocaine treatment and prenatal environment interact to disrupt intergenerational maternal behavior in rats. Behav Neurosci. 2005; 119(6):1605-1618. [PubMed: 16420163]

39. Johns JM, Lubin DA, Lieberman JA, Lauder JM. Developmental effects of prenatal cocaine exposure on 5-HT1A receptors in male and female rat offspring. Dev Neurosci. 2002; 24(6):522530. [PubMed: 12697990]

40. Johns JM, Noonan LR, Zimmerman LI, Li L, Pedersen CA. Effects of chronic and acute cocaine treatment on the onset of maternal behavior and aggression in Sprague-Dawley rats. Behav Neurosci. 1994; 108(1):107-112. [PubMed: 8192835]

41. Joseph, R. Neuropsychiatry, neuropsychology, clinical neuroscience: emotion, evolution, cognition, language, memory, brain damage, and abnormal behavior. 2nd edition. Lippincott Williams \& Wilkins; 1996. Limbic system social emotional development.

42. Jurgens U. The role of the periaqueductal grey in vocal behaviour. Behav Brain Res. 1994; 62(2): 107-117. [PubMed: 7945960]

43. Jurgens U. The neural control of vocalization in mammals: a review. J Voice. 2009; 23(1):1-10. [PubMed: 18207362] 
44. Kabitzke PA, Wiedenmayer CP. Effects of the stimulus and chamber size on unlearned fear across development. Behav Processes. 2011; 86(2):257-262. [PubMed: 21216279]

45. Keller RW Jr, Snyder-Keller A. Prenatal cocaine exposure. Ann N Y Acad Sci. 2000; 909:217232. [PubMed: 10911932]

46. Kraszpulski M, Dickerson PA, Salm AK. Prenatal stress affects the developmental trajectory of the rat amygdala. Stress. 2006; 9(2):85-95. [PubMed: 16895832]

47. Kuwagata M, Saito Y, Usumi K, Ono H, Nagao T. Disruption of brain development in male rats exposed prenatally to 5-bromo-2' -deoxyuridine. Congenital Anomalies. 2001; 41:312-320.

48. LaGasse LL, Neal AR, Lester BM. Assessment of infant cry: acoustic cry analysis and parental perception. Ment Retard Dev Disabil Res Rev. 2005; 11(1):83-93. [PubMed: 15856439]

49. Larson CR, Kistler MK. Periaqueductal gray neuronal activity associated with laryngeal EMG and vocalization in the awake monkey. Neurosci Lett. 1984; 46(3):261-266. [PubMed: 6738919]

50. Lee CT, Chen J, Hayashi T, Tsai SY, Sanchez JF, Errico SL, et al. A mechanism for the inhibition of neural progenitor cell proliferation by cocaine. PLoS Med. 2008; 5(6):e117. [PubMed: 18593214]

51. Lee CT, Chen J, Worden LT, Freed WJ. Cocaine causes deficits in radial migration and alters the distribution of glutamate and GABA neurons in the developing rat cerebral cortex. Synapse. 2011; 65(1):21-34. [PubMed: 20506319]

52. Lee HC, Yamanouchi K, Nishihara M. Effects of perinatal exposure to phthalate/adipate esters on hypothalamic gene expression and sexual behavior in rats. J Reprod Dev. 2006; 52(3):343-352. [PubMed: 16493179]

53. Lee T, Kim JJ. Differential effects of cerebellar, amygdalar, and hippocampal lesions on classical eyeblink conditioning in rats. J Neurosci. 2004; 24(13):3242-3250. [PubMed: 15056703]

54. Lester, BM. A biosocial model of infant cry. In: Lipsitt, L.; Rovee-Collier, C., editors. Advances in Infancy Research. Norwood, NY: Ablex; 1984. p. 167-212.

55. Lester BM. Prediction of developmental outcome from acoustic analysis in term and preterm infants. Pediatrics. 1987; 80:529-534. [PubMed: 3658572]

56. Lester BM, Corwin MJ, Sepkoski C, Seifer R, Peucker M, McLaughlin S, et al. Neurobehavioral syndromes in cocaine-exposed newborn infants. Child Dev. 1991; 62(4):694-705. [PubMed: 1935340]

57. Lester BM, Tronick EZ, LaGasse L, Seifer R, Bauer CR, Shankaran S, et al. The maternal lifestyle study: effects of substance exposure during pregnancy on neurodevelopmental outcome in 1month-old infants. Pediatrics. 2002; 110(6):1182-1192. [PubMed: 12456917]

58. Leventhal JM, Forsyth BW, Qi K, Johnson L, Schroeder D, Votto N. Maltreatment of children born to women who used cocaine during pregnancy: a population-based study. Pediatrics. 1997; 100(2):E7. [PubMed: 9233978]

59. Lewandowski TA, Ponce RA, Charleston JS, Hong S, Faustman EM. Changes in cell cycle parameters and cell number in the rat midbrain during organogenesis. Brain Res Dev Brain Res. 2003; 141(1-2):117-128.

60. Lewis MW, Phillips G, Bowser M, DeLuca S, Johnson HL, Rosen TS. Cocaine-exposed infant behavior during Still-Face: risk factor analyses. Am J Orthopsychiatry. 2009; 79(1):60-70. [PubMed: 19290726]

61. Li YQ, Rao ZR, Shi JW. Midbrain periaqueductal gray neurons with substance P-or enkephalinlike immunoreactivity send projection fibers to the nucleus accumbens in the rat. Neurosci Lett. 1990; 119(2):269-271. [PubMed: 1704115]

62. Mallo T, Matrov D, Koiv K, Harro J. Effect of chronic stress on behavior and cerebral oxidative metabolism in rats with high or low positive affect. Neuroscience. 2009; 164(3):963-974. [PubMed: 19706319]

63. Mandyam CD, Crawford EF, Eisch AJ, Rivier CL, Richardson HN. Stress experienced in utero reduces sexual dichotomies in neurogenesis, microenvironment, and cell death in the adult rat hippocampus. Dev Neurobiol. 2008; 68(5):575-589. [PubMed: 18264994]

64. Mayer AD, Rosenblatt JS. A method for regulating the duration of pregnancy and the time of parturition in Sprague-Dawley rats (Charles River CD strain). Dev Psychobiol. 1998; 32(2):131136. [PubMed: 9526688] 
65. Mayer DJ. Analgesia produced by electrical stimulation of the brain. Prog Neuropsychopharmacol Biol Psychiatry. 1984; 8(4-6):557-564. [PubMed: 6397776]

66. Middlemis-Brown JE, Johnson ED, Blumberg MS. Separable brainstem and forebrain contributions to ultrasonic vocalizations in infant rats. Behav Neurosci. 2005; 119(4):1111-1117. [PubMed: 16187838]

67. Moriceau S, Roth TL, Okotoghaide T, Sullivan RM. Corticosterone controls the developmental emergence of fear and amygdala function to predator odors in infant rat pups. Int J Dev Neurosci. 2004; 22(5-6):415-422. [PubMed: 15380840]

68. Nelson CJ, Meter KE, Walker CH, Ayers AA, Johns JM. A dose-response study of chronic cocaine on maternal behavior in rats. Neurotoxicol Teratol. 1998; 20(6):657-660. [PubMed: 9831128]

69. Newman JD. Neural circuits underlying crying and cry responding in mammals. Behav Brain Res. 2007; 182(2):155-165. [PubMed: 17363076]

70. Nixon K, Crews FT. Temporally specific burst in cell proliferation increases hippocampal neurogenesis in protracted abstinence from alcohol. J Neurosci. 2004; 24(43):9714-9722. [PubMed: 15509760]

71. Noonan MA, Choi KH, Self DW, Eisch AJ. Withdrawal from cocaine self-administration normalizes deficits in proliferation and enhances maturity of adult-generated hippocampal neurons. J Neurosci. 2008; 28(10):2516-2526. [PubMed: 18322096]

72. Nunez JL, Lauschke DM, Juraska JM. Cell death in the development of the posterior cortex in male and female rats. J Comp Neurol. 2001; 436(1):32-41. [PubMed: 11413544]

73. Nunez JL, Sodhi J, Juraska JM. Ovarian hormones after postnatal day 20 reduce neuron number in the rat primary visual cortex. J Neurobiol. 2002; 52(4):312-321. [PubMed: 12210098]

74. Oomen CA, Girardi CE, Cahyadi R, Verbeek EC, Krugers H, Joels M, et al. Opposite effects of early maternal deprivation on neurogenesis in male versus female rats. PLoS ONE. 2009; 4(1):e3675. [PubMed: 19180242]

75. Pagani JH, Rosen JB. The medial hypothalamic defensive circuit and 2,5-dihydro-2,4,5trimethylthiazoline (TMT) induced fear: comparison of electrolytic and neurotoxic lesions. Brain Res. 2009; 1286:133-146. [PubMed: 19559688]

76. Porges, SW.; Lewis, GF. The polyvagal hypothesis: com- mon mechanisms mediating auto- nomic regulation, vocalizations and listening. In: Brudzynski, SM., editor. Handbook of Mam- malian Vocalization: An Integrative Neuroscience Approach. Oxford, UK: Academic Press; 2010. p. 255-264.

77. Porter FL, Miller RH, Marshall RE. Neonatal pain cries: effect of circumcision on acoustic features and perceived urgency. Child Dev. 1986; 57(3):790-802. [PubMed: 3720404]

78. Prescott R. Infant cry sound; developmental features. J Acoust Soc Am. 1975; 57(5):1186-1191. [PubMed: 1127173]

79. Rakic P, Caviness VS Jr. Cortical development: view from neurological mutants two decades later. Neuron. 1995; 14(6):1101-1104. [PubMed: 7605626]

80. Rice D, Barone S Jr. Critical periods of vulnerability for the developing nervous system: evidence from humans and animal models. Environ Health Perspect. 2000; 108(Suppl 3):511-533. [PubMed: 10852851]

81. Sandkuhler J, Willmann E, Fu QG. Characteristics of midbrain control of spinal nociceptive neurons and nonsomatosensory parameters in the pentobarbital-anesthetized rat. J Neurophysiol. 1991; 65(1):33-48. [PubMed: 1999730]

82. Scheiner E, Hammerschmidt K, Jurgens U, Zwirner P. Acoustic analyses of developmental changes and emotional expression in the preverbal vocalizations of infants. J Voice. 2002; 16(4): 509-529. [PubMed: 12512639]

83. Shair HN, Brunelli SA, Masmela JR, Boone E, Hofer MA. Social, thermal, and temporal influences on isolation-induced and maternally potentiated ultrasonic vocalizations of rat pups. Dev Psychobiol. 2003; 42(2):206-222. [PubMed: 12555284]

84. St James-Roberts I, Halil T. Infant crying patterns in the first year: normal community and clinical findings. J Child Psychol Psychiatry. 1991; 32(6):951-968. [PubMed: 1744198] 
85. St James-Roberts I, Plewis I. Individual differences, daily fluctuations, and developmental changes in amounts of infant waking, fussing, crying, feeding, and sleeping. Child Dev. 1996; 67(5):25272540. [PubMed: 9022254]

86. Stern JM, Thomas DA, Rabii J, Barfield RJ. Do pup ultrasonic cries provoke prolactin secretion in lactating rats? Horm Behav. 1984; 18(1):86-94. [PubMed: 6706322]

87. Stevenson JR, Schroeder JP, Nixon K, Besheer J, Crews FT, Hodge CW. Abstinence following alcohol drinking produces depression-like behavior and reduced hippocampal neurogenesis in mice. Neuropsychopharmacology. 2009; 34(5):1209-1222. [PubMed: 18563059]

88. Takahashi LK, Hubbard DT, Lee I, Dar Y, Sipes SM. Predator odor-induced conditioned fear involves the basolateral and medial amygdala. Behav Neurosci. 2007; 121(1):100-110. [PubMed: 17324054]

89. Vaido AI, Shiryaeva NV, Vshivtseva VV. Effect of prenatal stress on proliferative activity and chromosome aberrations in embryo brain in rats with different excitability of the nervous system. Bull Exp Biol Med. 2000; 129(4):380-382. [PubMed: 10977927]

90. van der Wal MF, van EM, Bonsel GJ. Stress and emotional problems during pregnancy and excessive infant crying. J Dev Behav Pediatr. 2007; 28(6):431-437. [PubMed: 18091087]

91. Weinstock M. Gender differences in the effects of prenatal stress on brain development and behaviour. Neurochem Res. 2007; 32(10):1730-1740. [PubMed: 17406975]

92. Wetzel DM, Kelley DB, Campbell BA. Central control of ultrasonic vocalizations in neonatal rats: I. Brain stem motor nuclei. J Comp Physiol Psychol. 1980; 94(4):596-605. [PubMed: 7410625]

93. Wiedenmayer CP. Plasticity of defensive behavior and fear in early development. Neurosci Biobehav Rev. 2009; 33(3):432-441. [PubMed: 19073211]

94. Wohr M, Dahlhoff M, Wolf E, Holsboer F, Schwarting RK, Wotjak CT. Effects of genetic background, gender, and early environmental factors on isolation-induced ultrasonic calling in mouse pups: an embryo-transfer study. Behav Genet. 2008; 38(6):579-595. [PubMed: 18712592]

95. Wurmser H, Rieger M, Domogalla C, Kahnt A, Buchwald J, Kowatsch M, et al. Association between life stress during pregnancy and infant crying in the first six months postpartum: a prospective longitudinal study. Early Hum Dev. 2006; 82(5):341-349. [PubMed: 16472948]

96. Xiao D, Zhang L. Upregulation of Bax and Bcl-2 following prenatal cocaine exposure induces apoptosis in fetal rat brain. Int J Med Sci. 2008; 5(6):295-302. [PubMed: 18974856]

97. Yamaguchi M, Suzuki T, Seki T, Namba T, Juan R, Arai H, et al. Repetitive cocaine administration decreases neurogenesis in adult rat hippocampus. Ann N Y Acad Sci. 2004; 1025:351-362. [PubMed: 15542736]

98. Yee N, Schwarting RK, Fuchs E, Wohr M. Juvenile stress potentiates aversive 22-kHz ultrasonic vocalizations and freezing during auditory fear conditioning in adult male rats. Stress. 2012

99. Zeskind PS, Lester BM. Acoustic features and auditory perceptions of the cries of newborns with prenatal and perinatal complications. Child Dev. 1978; 49(3):580-589. [PubMed: 710187]

100. Zeskind, PS.; Lester, BM. Analysis of infant crying. In: Singer, L.; Zeskind, PS., editors. Biobehavioral assessment of the infant. New York: The Guilford Press; 2001. p. 149-166.

101. Zeskind PS, McMurray MS, Garber KA, Neuspiel JM, Cox ET, Grewen KM, et al. Development of translational methods in spectral analysis of human infant crying and rat pup ultrasonic vocalizations for early neurobehavioral assessment. Front Psychiatry. 2011; 2:56. [PubMed: 22028695]

102. Zhao Z, Yang Y, Walker DL, Davis M. Effects of substance P in the amygdala, ventromedial hypothalamus, and periaqueductal gray on fear-potentiated startle. Neuropsychopharmacology. 2009; 34(2):331-340. [PubMed: 18418359]

103. Zimmerberg B, Kim JH, Davidson AN, Rosenthal AJ. Early deprivation alters the vocalization behavior of neonates directing maternal attention in a rat model of child neglect. Ann N Y Acad Sci. 2003; 1008:308-313. [PubMed: 14998903]

104. Zimmerberg B, Rosenthal AJ, Stark AC. Neonatal social isolation alters both maternal and pup behaviors in rats. Dev Psychobiol. 2003; 42(1):52-63. [PubMed: 12471636] 


\section{Highlights}

1. Effects of prenatal cocaine on vocalizations were assessed in offspring.

2. Prenatal cocaine is associated with age- and sex-dependent vocalization changes.

3. Prenatal cocaine is associated with age- and sex-dependent limbic region changes.

4. Developmental differences in limbic regions correlate with altered USV acoustics. 
A
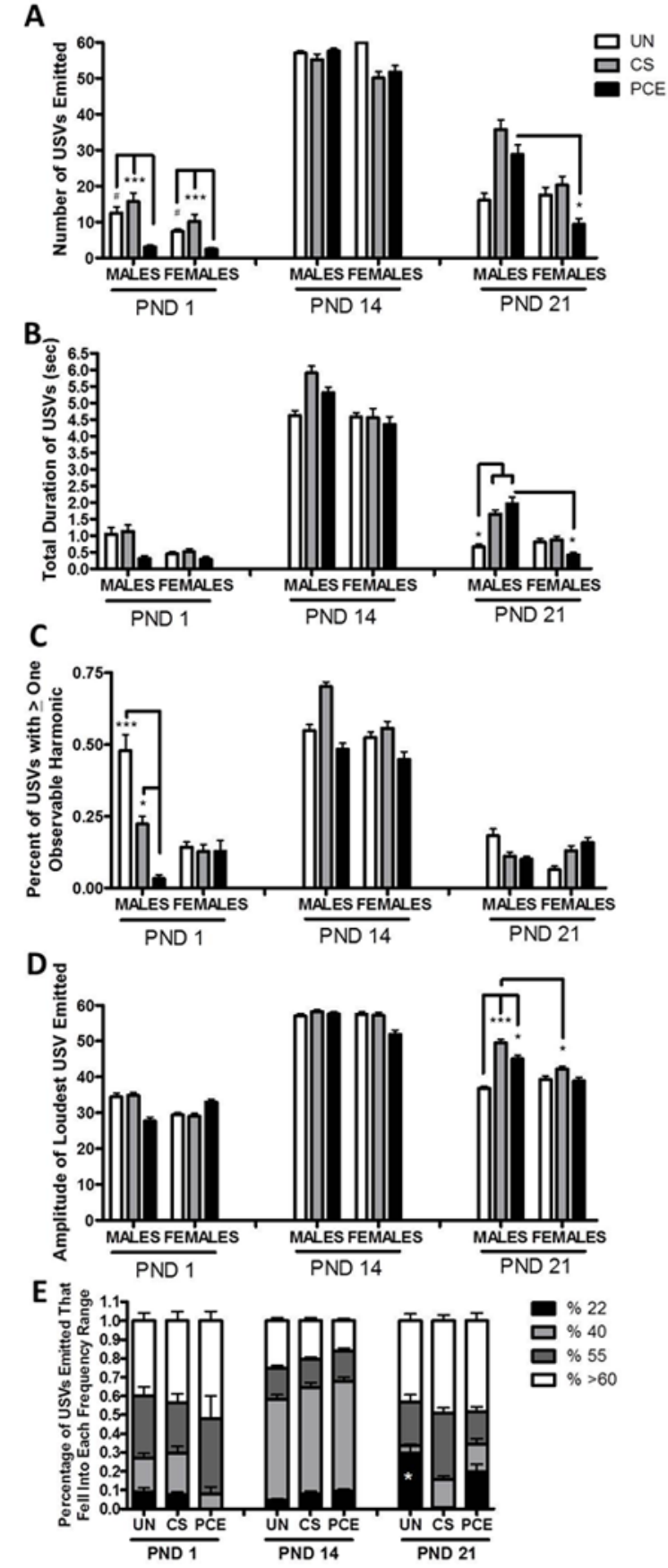

Figure 1. Developmental Variations in Vocalizations on PND 1, 14, and 21 in rat male and female offspring following PCE, CS, or no prenatal exposure

(A) Total number of USVs emitted by offspring on each respective test day. On PND 1 PCE offspring emitted fewer USVs compared to controls. On PND 21 PCE males emitted more USVs than PCE females. (B) Total duration of USVs. No significant differences were observed in total duration of USVs on PND 1 or 14. By PND 21 PCE and CS males showed a longer total duration of USVs compared to UN males. PCE males also had a greater total duration than PCE females. (C) Percentage of USVs emitted with at least one observable harmonic. PCE males showed a decrease in the percentage of calls emitted with an observable harmonic on PND 1 but not significant differences were observed between 
groups on PND 14 or 21. (D) Amplitude of the Loudest USV emitted. No significant differences in amplitude were observed on PND 1 or 14. On PND 21 PCE and CS males emitted USVs with louder amplitude than UN males. CS males also emitted USVs with at louder amplitudes than CS females. (E) Percentage of vocalizations emitted that fell into the $22,40,55$, or greater than $60 \mathrm{kHz}$ range for female offspring at each age of testing. PCE and CS female offspring emitted less $22 \mathrm{kHz}$ USV s compared to UN females. Males (not shown) showed a similar pattern at each age but did not significantly differ in percentage of $22 \mathrm{kHz}$ calls on PND 21. $(* * * \mathrm{p}<0.001, * * \mathrm{p}<0.01, * \mathrm{p}<0.05 ; \# \mathrm{p}=0.06 ; \mathrm{N}=10-11$ animals per treatment group and sex analyzed for vocalizations) 

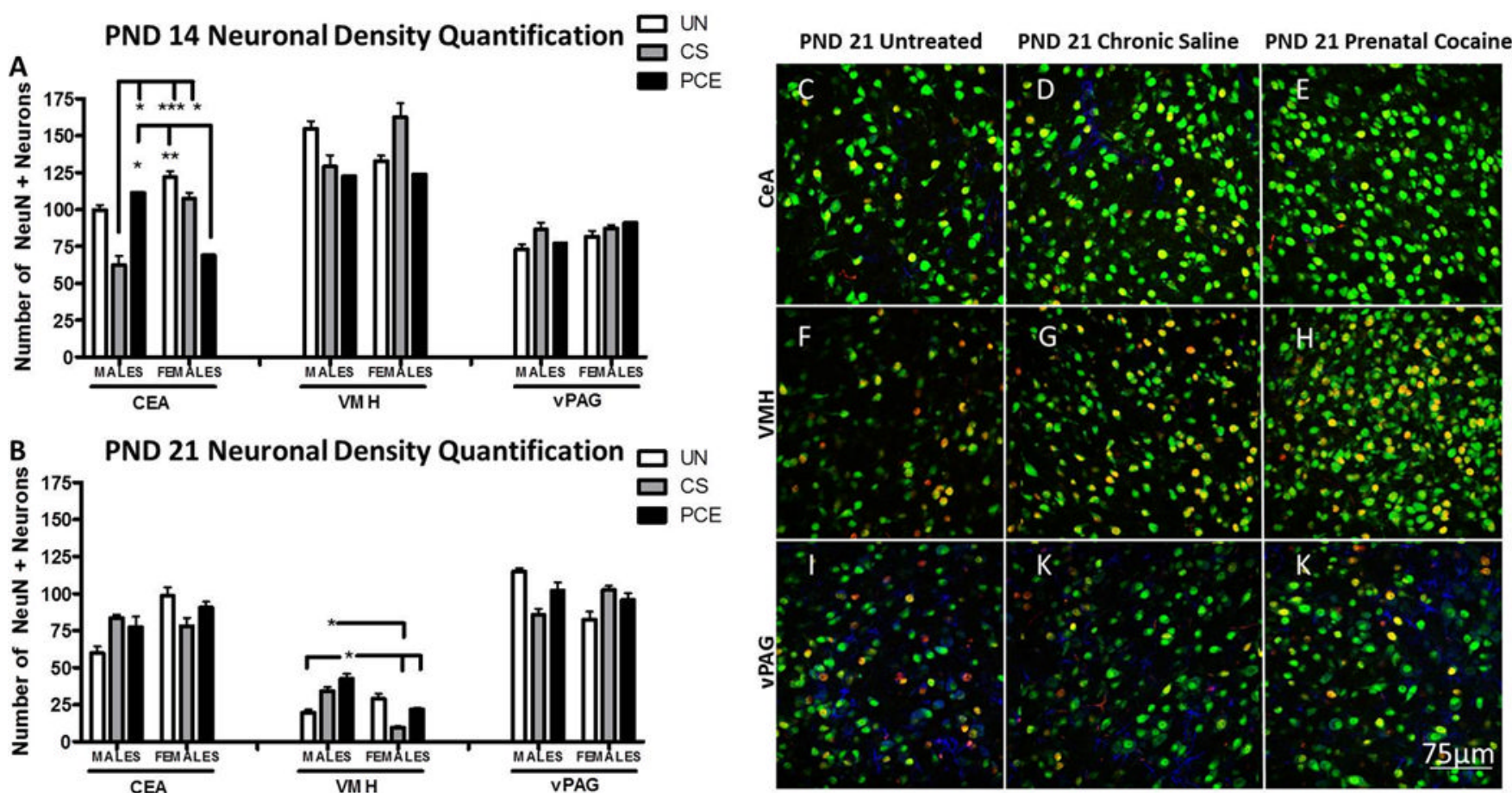

Figure 2. PND 14 and $21 \mathrm{CeA}$, VMH, and vPAG development in offspring following PCE, CS, or no prenatal exposure

(A) PND 14 quantitative depiction of neuronal density in the CeA, VMH, and vPAG. PCE female offspring on PND 14 showed a decrease in neuronal density in the CeA compared to UN female and PCE male offspring but did not significantly differ from controls in the VMH or dPAG. (B) PND 21 quantitative depiction of neuronal density in the CeA, VMH, and vPAG. PCE male offspring showed an increase in neuronal density in the VMH compared to UN male and PCE and CS female offspring. CS males showed an increase in neuronal density in the VMH compared to CS females. No significant differences were observed in the CeA or vPAG. (C-E) PND 21 representative images of the CeA at 40X magnification from UN, CS, and PCE male offspring respectively. (F-H) PND 21 representative images of the $\mathrm{VMH}$ at $40 \mathrm{X}$ magnification from $\mathrm{UN}, \mathrm{CS}$, and PCE male offspring respectively. (I-K) PND 21 representative images of the vPAG at 40X magnification from UN, CS, and PCE male offspring respectively. White line in the bottom right of Figure $\mathrm{K}$ is $75 \mu \mathrm{m}$ scale bar for all $40 \mathrm{X}$ representative images. (*** $\mathrm{p}<0.001$, $* * \mathrm{p}<0.01, * \mathrm{p}<0.05 ; \mathrm{N}=8-11$ (PND 14) and 8-10 (PND 21) animals per treatment group and sex analyzed for CeA, VMH, and $\mathrm{vPAG})$. 

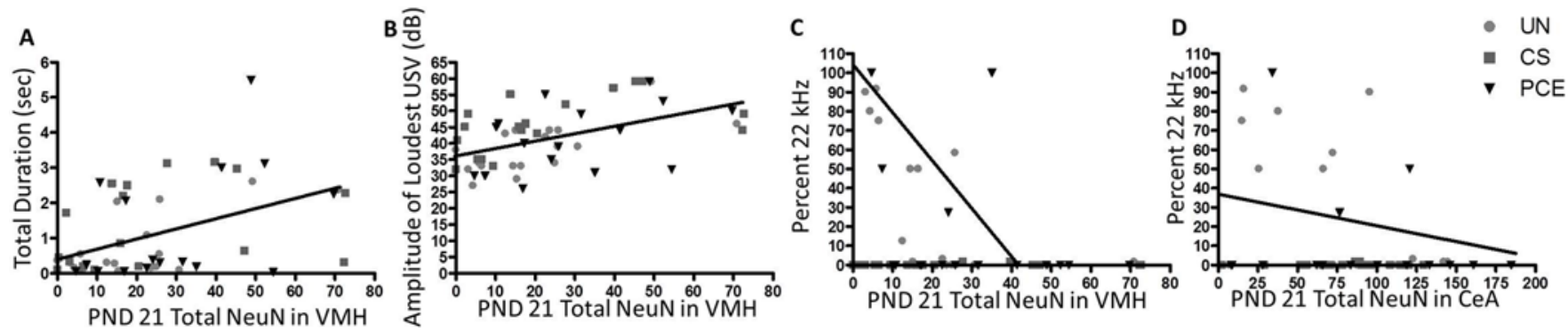

Figure 3. PND 21 Correlations Between Variations in Vocalizations and Limbic Region Development

(A) Correlation between total duration of USVs on PND 21 and the percentage of BrdUpositive cells that co-label as a mature neuron in the VMH on PND 21 showing a significant positive relationship. (B) Correlation between amplitude of the loudest call on PND 21 and the percentage of BrdU-positive cells that co-label as a mature neuron in the VMH on PND 21 showing a significant positive relationship. (C) Correlation between percentage of USVs that were in the $22 \mathrm{kHz}$ range on PND 21 and the total number of NeuN-positive mature neurons in the VMH on PND 21 showing a significant inverse relationship. (D) Correlation between percentage of USVs that were in the $22 \mathrm{kHz}$ range on PND 21 and the total number of NeuN-positive mature neurons in the CeA on PND 21 showing a significant inverse relationship. 8-10 animals per treatment group and sex analyzed CeA and VMH correlations with percentage of $22 \mathrm{kHz}$ USVs). 